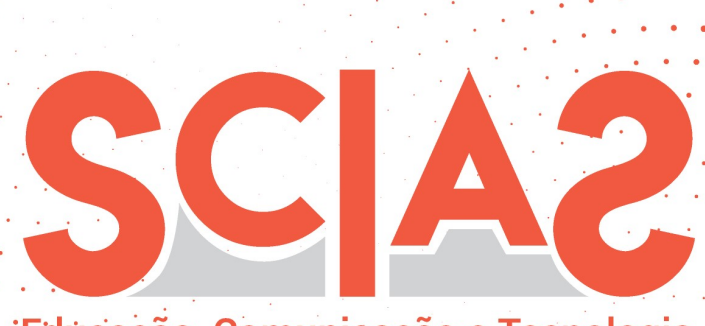

Educuçaçã̉o, Comunicação e Tecnologia

Atribuição BB CY 4.0

\title{
Formação continuada pela internet durante a quarentena: relato de experiência
}

Paola Verdun ${ }^{1}$

\section{Resumo}

As tecnologias digitais estão presentes na vida pessoal e profissional de algumas pessoas há pelo menos uma década. Este artigo tem como objetivo discutir a possibilidade de utilização de algumas tecnologias digitais por professores para a formação continuada durante o período de pandemia pelo covid-19 (novo coronavírus) no Brasil, que vem ganhando ainda mais espaço no cotidiano dos profissionais devido ao isolamento social. Metodologicamente, optou-se por exibir quatro ofertas gratuitas de cursos aos quais foi possível ter acesso entre 18 de março e 18 de julho deste ano, o que pode viabilizar um processo de educação continuada. O estudo enfocou as modalidades de Educação a Distância e Ensino Remoto. Também é proposta uma breve análise em diálogo com Larrosa (1994) e outros autores, mostrando que o processo de educação continuada pela Internet pode ser constituído pela criação de uma experiência de si e pela transformação da subjetividade de uma professora.

\section{Palavras-chave}

Formação continuada. Ensino remoto. Isolamento social. Quarentena.

Recebido em: 29/07/2020

Aprovado em: 26/01/2021

1 Mestra em Educação, Especialista em Gestão e Docência no Ensino Superior, Licenciada em Dança. Atualmente atua como Educadora Social.

E-mail: paola.verduno8@gmail.com 


\title{
Continuing education through the internet during the quarantine: experience report
}

\begin{abstract}
Digital technologies have been present in the personal and professional lives of some people for at least a decade. This article aims to discuss the possibility of using some digital technologies by teachers for continuing education during the pandemic period by covid-19 (new coronavirus) in Brazil, which has been gaining even more space in the daily lives of professionals due to social isolation. Methodologically it was chosen to show four free offers of courses to which it was possible to have access between March 18th and July 31st of this year, which can enable a process of continuing education. The study focused on the Distance Education and Remote teaching modalities. It is also proposed a brief analysis in dialogue with Larrosa (1994) and other authors, showing that the process of continuing education through the internet can be constituted by the creation of an experience of self and the transformation of a teacher's subjectivity.
\end{abstract}

\section{Keywords}

Teaching-learning process. Digital Culture. Subjectivity. Teacher. Student. 


\section{Introdução}

O contexto da pandemia pelo covid-19 (novo coronavírus) no Brasil no ano de 2020 tem provocado diversas reflexões e atitudes voltadas para a vida espiritual, pessoal e profissional do indivíduo. Dentre as práticas diárias, as quais também contemplam as atividades laborais, é cada dia mais intenso o uso das tecnologias digitais, já presentes na vida pessoal e profissional de alguns sujeitos há pelo menos uma década. Seja para lazer ou trabalho, é quase impossível, na atualidade, trabalhar ou se comunicar sem estar digitalmente incluído. Entre práticas docentes, de formação continuada, lazer e outras, chegam por e-mail, whatsapp e outros canais, variados convites para eventos acadêmicos, lives2 e webinars 3 transmitidos por facebook, youtube, instagram e outros canais; cursos e vídeo-aulas oferecidas por diferentes plataformas educacionais brasileiras, entre tantas outras opções, para quem decidiu fazer uso do tempo pela internet no computador, tablet, celular e outros meios, e/ou aprimorar conhecimentos e manter-se atualizado durante o período de isolamento social. Muitas dessas opções são inclusive oferecidas de forma gratuita e fornecem certificado de participação, facilitando os processos de atualização e formação profissionais, sem sair de casa. E é no aspecto da possibilidade de uma formação continuada pela internet neste momento de isolamento e de manter o aprimoramento profissional nas condições que se apresentam que se concentra este relato de experiência.

Fazendo um recorte sobre quais ferramentas estão sendo usadas por professores neste período de isolamento social, por exemplo, nota-se diversas instituições ofertando algumas horas de formação para seus seguidores/alunos/profissionais da educação aprenderem algo novo ou se aprofundarem no que já conhecem, dentre as ferramentas digitais disponíveis para ensinar. Assim, através de aplicativos como zoom, google meet, lives no instagram ou youtube, torna-se possível aprender ou aprimorar outras formas de trabalhar com educação de forma digital, visto que esses novos modos de operar nossas práticas docentes se estabelecem com mais força nesta situação

\footnotetext{
${ }^{2}$ Lives são transmissões ao vivo pelas redes sociais facebook, instagram, assim como nos aplicativos zoom, google meet e outros.

3 Conferência online ou videoconferência com intuito educacional.
} 
em que vivemos, e parecem ter vindo para ficar. Dentre as modalidades educacionais escolhidas para discussão neste trabalho destacam-se, primeiro, as metodologias ensinadas pela internet que compreendem as TDICs Tecnologias Educacionais da Informação e Comunicação - utilizadas pelas plataformas educacionais EAD (Educação a Distância), cujas bases se sustentam por legislação própria e, segundo, as metodologias ativas possíveis de se utilizar no Ensino Remoto.

Destaca-se que este relato não se concentra em discutir diferenciações conceituais ou questões relacionadas à formação inicial, profissionalização docente ou políticas de formação ao tratar da formação continuada; ou, se é necessária ou está sendo realizada adequadamente por poderes públicos e professores ou não. E sim, traz uma experiência que pode ser considerada formação continuada, realizada em cursos gratuitos livres, pela internet, ou seja, utilizando tecnologias educacionais para tal, durante o período de quarentena ou isolamento social4 recomendado para evitar o contágio de covid-19 em Porto Alegre/RS. Portanto, o presente trabalho tem o objetivo de discutir acerca da possibilidade de utilização de algumas tecnologias digitais por professores para formação continuada, as quais vem ganhando ainda mais espaço no cotidiano dos sujeitos professores devido ao maior tempo em casa.

Metodologicamente, escolheu-se mostrar quatro ofertas gratuitas de curso, às quais foi possível ter acesso entre 18 de março e 18 de julho do corrente ano, que podem possibilitar uma formação continuada. Propõe-se uma breve análise a partir de Larrosa (1994) para discutir aspectos relacionados a processos de transformação da subjetividade e da experiência de si de uma professora.

\section{Formação Continuada e EAD}

Considera-se, para o presente estudo, a formação continuada sugerida por alguns autores, ou seja, aquela desenvolvida como treinamento para melhora de desempenho ou, ainda, como um processo de desenvolvimento profissional

\footnotetext{
4 Optou- se por utilizar os termos isolamento social ou quarentena para referir-se ao tempo permanecido em casa para evitar o contágio pelo novo coronavírus.
} 
mais experiencial do que técnica (CASTRO; AMORIM, 2015). A despeito das discussões conceituais sobre o tema, e das implicações quanto a interesses e centralização e um caráter mercadológico proposto por alguns estudos, esta proposta parte de uma situação específica de pandemia, onde proliferam muitas e diferentes ofertas gratuitas que possibilitam algum tipo de treinamento pela internet para professores desempenharem de novas formas a sua prática profissional.

Mais uma vez, o cuidado com as perspectivas de treinamento ou reciclagem é necessário para não se cair no mesmo erro de imaginar a formação para a docência online a partir de conceitos fechados, conteúdos pré-definidos, abordagens "ideais", que, seguramente, pode ser facilmente rejeitada e ignorada pelos docentes. (PRETTO; RICCIO, 2010, p. 162).

Assim, esse trabalho vem relatar como se apresentam algumas das novas possibilidades e flexibilidades que surgem para que o professor possa continuar sua formação mesmo no contexto da pandemia. E, ainda, como o professor se relaciona com o processo de aprendizagem das ferramentas propostas para ensinar. Há dez anos já se considerava a existência de uma nova forma de pensar e de se produzir conhecimentos, com

uma outra lógica que considera os processos comunicacionais quase instantâneos - como elementos transformadores das realidades locais. São os twitters, sms (short message system mensagens curtas pelo celular), redes de relacionamento sociais como Orkut, Facebook, My Space, Quepassa, entre tantos outros que trazem novos elementos para a produção e sentido e que desafiam, literalmente, a educação. (PRETTO; RICCIO, 2010, p. 157).

Pode-se apontar as redes sociais atuais (youtube, facebook, instagram, telegram), entre outras, como sucessoras daquelas citadas acima, que agora oferecem uma infinidade ainda maior de opções que podem ser observadas na hora de escolher um processo de formação continuada, especialmente no momento atual, em que muitas transformações já vem acontecendo no âmbito educacional.

A EAD foi instituída pelo Governo Federal sob o decreto número 9.057, de 25 de maio de 2017, estabelecendo as diretrizes para a educação nacional considerando-a uma modalidade educacional 
na qual a mediação didático pedagógica nos processos de ensino e aprendizagem ocorra com a utilização de meios e tecnologias de informação e comunicação, com pessoal qualificado, com políticas de acesso, com acompanhamento e avaliação compatíveis, entre outros, e desenvolva atividades educativas por estudantes e profissionais da educação que estejam em lugares e tempos diversos. (BRASIL, 2017, p. 3).

Com o contexto de quarentena em que estamos, professores e educadores vêm enfrentando novos desafios ao precisar, por exigências institucionais, adequar suas atividades presenciais ao modelo remoto, momento para o qual não estávamos preparados. Assim, trabalhando em casa, o profissional se percebe também utilizando os cursos online para se preparar e propor atividades remotas aos seus alunos. Para conseguir algum êxito, profissionais podem recorrem a dicas de ferramentas que podem ser usadas neste caso. E é na possibilidade de formação continuada por e para a EAD que se concentra a próxima seção.

\section{Possibilidades de formação continuada por e para a EAD}

Para este trabalho foram selecionadas quatro experiências com cursos gratuitos online realizadas durante o período de isolamento social pela pandemia de coronavírus, as quais podem ser consideradas como formação continuada. Duas dessas experiências são as dos cursos Extensão em Tecnologias Educacionais e Formação de Professores: tela inteligente online e avaliação online. Ambas direcionam-se aos profissionais da EAD e nesta seção são tratadas relatando-se seu funcionamento e quais ferramentas podem ser trabalhadas pelos professores, descrevendo alguns detalhes que se julga relevantes.

A primeira experiência foi com o Sistema de Ensino Gaúcho - SEG, que oferece o curso Extensão em Tecnologias Educacionais, com certificado de 8 horas, disponibilizado por um Ambiente Virtual de Aprendizagem - AVA próprio, cujo acesso se dá por login e senha. Em um vídeo de abertura a parte introdutória contextualiza as TICs e TDICs, mostrando quais novidades são implicadas para os docentes no novo contexto do ensino pelas plataformas digitais; em uma apresentação de Powerpoint explica, entre outras coisas, os objetos de 
aprendizagem (AO) que podem ser vídeos, animações, simulações, áudios, imagens, hipertextos, entre outros, utilizados para ensinar diferentes conteúdos; além de disponibilizar tutoriais para baixar e usar as ferramentas indicadas. Com a ferramenta Cmaptools, que deve ser baixada para computador, é possível criar mapas conceituais (Figura 1) que podem ser usados para fixar conceitos e ligar elementos diferentes em um texto, criando um caminho para ensinar o conteúdo aos alunos.

Figura 1 - Exemplo de mapa conceitual criado no cmaptools

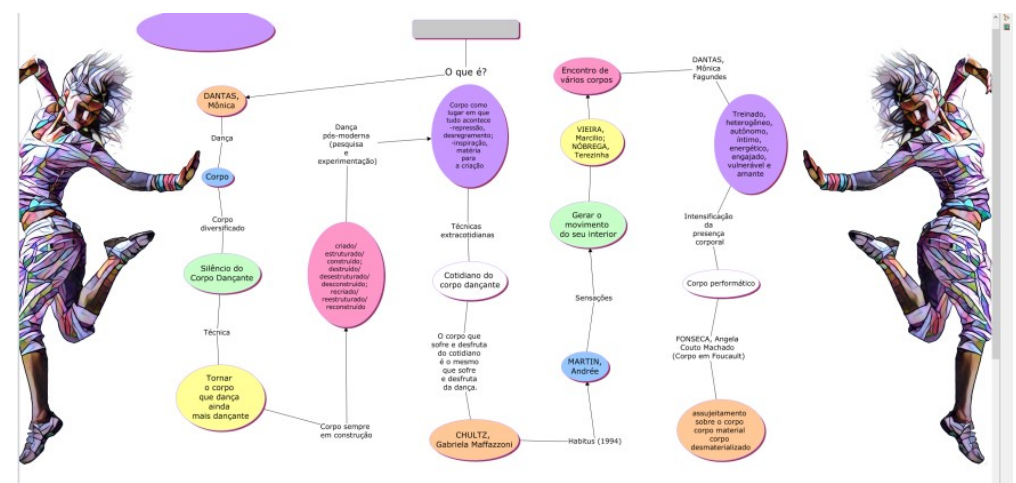

Fonte: Captura de tela da autora, 2020.

Através da plataforma online Canva é possível criar infográficos (Figura 2) definindo o conteúdo a ser ensinado, um problema ou uma questão a ser resolvida para apresentar através de um material gráfico em diferentes modelos - linha do tempo, informativo, negócios, educação, beneficência, entre outros.

Figura 2 - Tela de opções de templates de infográficos do canva

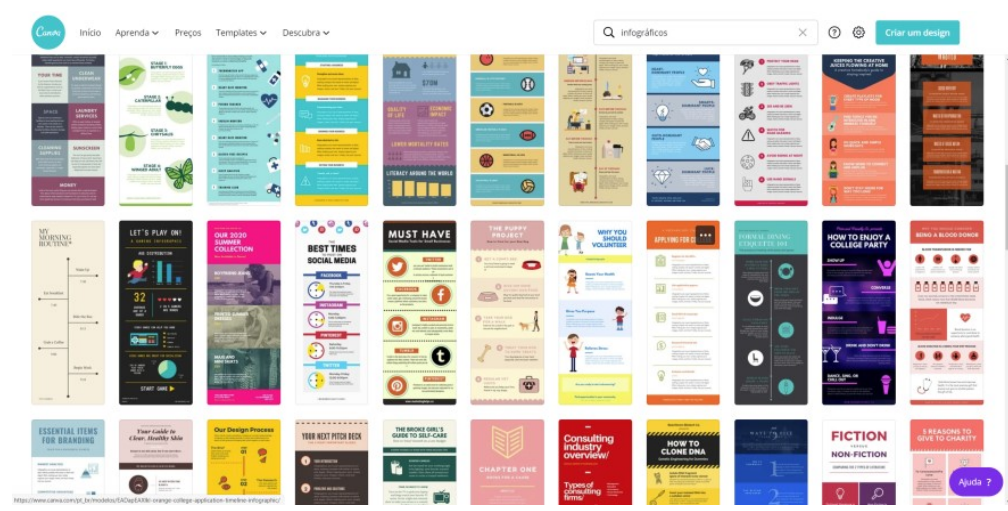

Fonte: Captura de tela da autora, 2020. 
Na plataforma online Powtoon é possível criar animações (Figura 3) com a apresentação do conteúdo da disciplina ou um contato com os alunos. Alguns dos templates inclusive trazem o tema covid-19 para trabalhar com uma turma escolar ou pessoas do departamento de uma empresa, por exemplo.

Figura 3 - Exemplos de templates de animação do powtoon

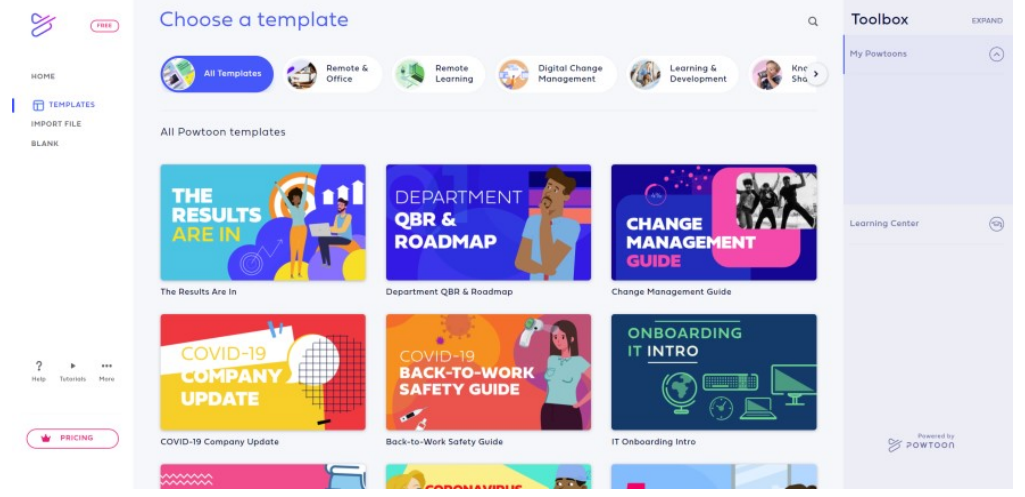

Fonte: Captura de tela da autora, 2020.

Pela ferramenta zoom meeting (Figura 4), aplicativo que também, mas não obrigatoriamente, pode ser baixado para uso no celular, tablet ou computador, pode-se realizar reuniões e vídeo-aulas com os alunos. Ao centro da tela fica a imagem do usuário, que pode ser uma fotografia sua quando não está sendo visto em tempo real; e as opções de uso da ferramenta se encontram na parte posterior da tela, quando utilizada pelo computador. Através dele também é possível gravar vídeos e postá-los pelo youtube, por exemplo. É necessário ter câmera e microfone para conseguir se comunicar com os demais participantes da reunião pelo zoom.

Figura 4 - Tela de reunião do zoom meeting

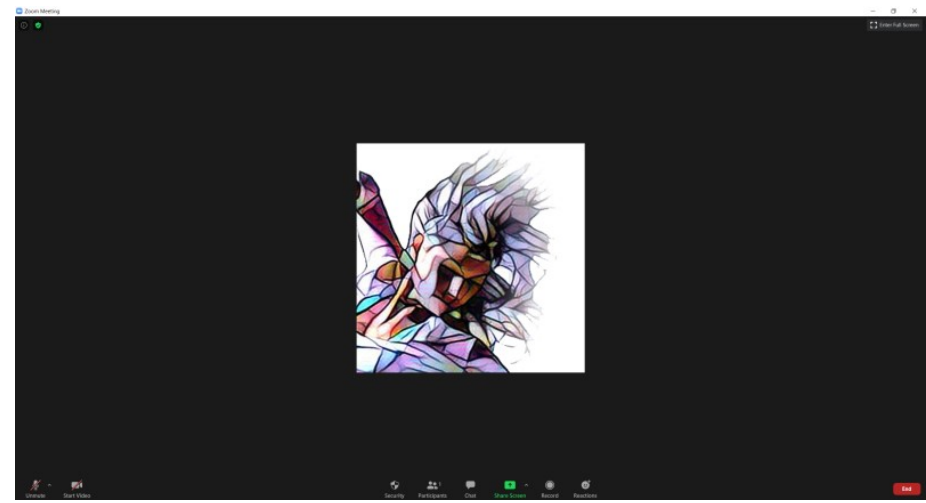

Fonte: Captura de tela da autora, 2020. 
Algumas dessas ferramentas oferecem recursos gratuitos, mas muitos pagos também, então o usuário precisa ficar atento caso não queira pagar pelo conteúdo que usa para criar suas aulas. É o caso de alguns elementos do canva e do powtoon.

A cada ferramenta experimentada o inscrito deve produzir algum conteúdo com temas de sua disciplina e disponibilizá-lo em um espaço destinado às postagens. Assim se pode ter acesso ao certificado e o AVA calcula o progresso do curso quando é marcado pelo "aluno" o conteúdo já visto. Neste caso, basta disponibilizar a tarefa para ser considerada concluída ou realizada, não sendo possível notar se o conteúdo foi visualizado ou corrigido por alguém.

Observa-se que em uma formação online o professor tem acesso aos mais variados meios de produção de conteúdo e material para ministrar suas aulas. No entanto, no caso deste curso, os conteúdos são disponibilizados e o inscrito acessa independente de um tutor, ou seja, a EAD se dá de forma assíncrona, sem diálogo em tempo real.

No caso da segunda experiência selecionada para este relato, o Curso de Formação de Professores: tela inteligente online e avaliação online, oferecido pelo Centro Universitário Araguaia - UniAraguaia, a comunicação é realizada de forma síncrona, com interação e diálogo em tempo real e feedback instantâneo por parte dos alunos. Em dois dias seguidos, oferecendo uma carga horária comprovada de 4 horas pelo aplicativo zoom meeting, o professor interagiu em tempo real com os inscritos ensinando-os como utilizar as ferramentas propostas. Neste caso o participante precisa ter acesso às ferramentas do google para poder participar da aula ao vivo.

Pensamos que as redes sociais virtuais na educação são um importante recurso de comunicação, interação e compartilhamento de ideias, informações e conhecimentos de forma colaborativa, e por estas características, tornam-se uma importante ferramenta que pode ser pesquisada e explorada potencialmente na área educacional. (SANTOS; MELIM; PANIAGO, 2017, p. 16-17). 
Neste caso, o professor conversou, fez perguntas, ensinou e tirou dúvidas dos participantes ao vivo, conduzindo-os a acessar e mexer nas ferramentas propostas, mantendo uma conversa informal e explicativa durante todo o tempo da aula. Como acessar o drive e o Google classroom pelo gmail (e-mail do Google); a partir daí, como acessar e criar os formulários que podem ser utilizados para avaliar as turmas, pelo Google forms; como acessar e usar a tela inteligente Google jamboard e o Padlet e suas possibilidades interativas de criação e colaboração junto com os alunos. Quando algum dos participantes tinha dúvidas, lançava no bate-papo do zoom, e o professor então parava tudo e recomeça a explicação, até que a dúvida ou dificuldade fosse resolvida. Tudo isso em tempo real, o que pode fazer as possibilidades de ensino e aprendizagem ampliarem-se significativamente.

Os ambientes virtuais de aprendizagem, organizados em torno de plataformas ou não agrupados enquanto estrutura única, mas amalgamados pelo projeto pedagógico dos cursos, constituem uma ambiência rica em possibilidade de diálogo com o conhecimento instituído, de construção de novos conhecimentos e culturas e de ampliação de visão de mundo de todos os partícipes desses processos. É essa navegação - melhor dizendo, esse flanar pelo ciberespaço -, que possibilita o caminhar em direção a uma formação para a docência online. Mas isso, se olharmos para o caminho e não para o resultado. (PRETTO; RICCIO, 2010, p. 165).

No Google classroom (Figura 5), ou Google sala de aula, encontram-se as disciplinas que o professor cria para lançar às turmas os conteúdos, atalhos para imagens, textos e sites, entre outros. O professor pode personalizar a tela com cores e imagens ou manter em branco.

Figura 5 - Tela do Google classroom

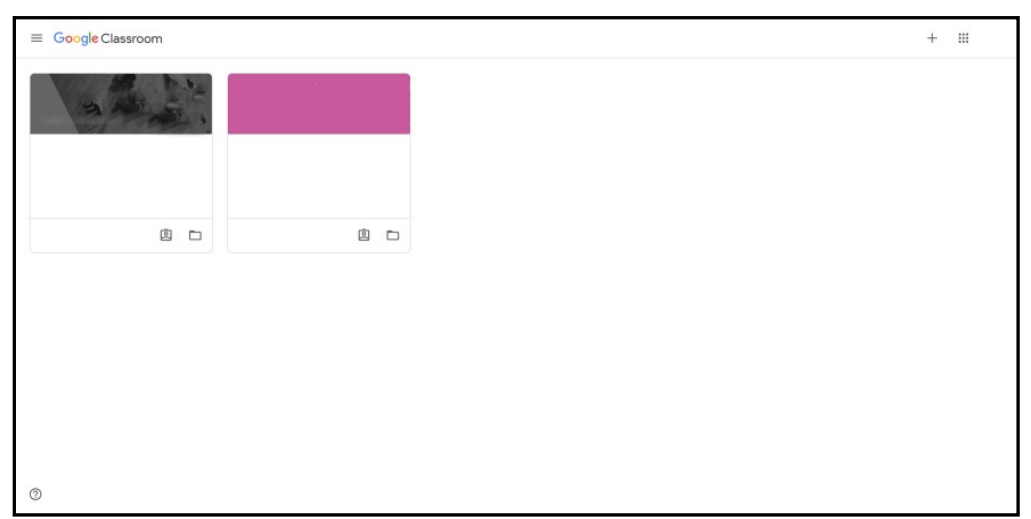

Fonte: Captura de tela da autora, 2020. 
O Google jamboard (Figura 6) pode ser utilizado para interagir com uma turma em que cada aluno, conectado pelo seu gmail, pode adicionar conteúdos imagens, textos, post-its, desenhos, vídeos, gifs, entre outros elementos de informação.

Figura 6 - Tela do Google jamboard

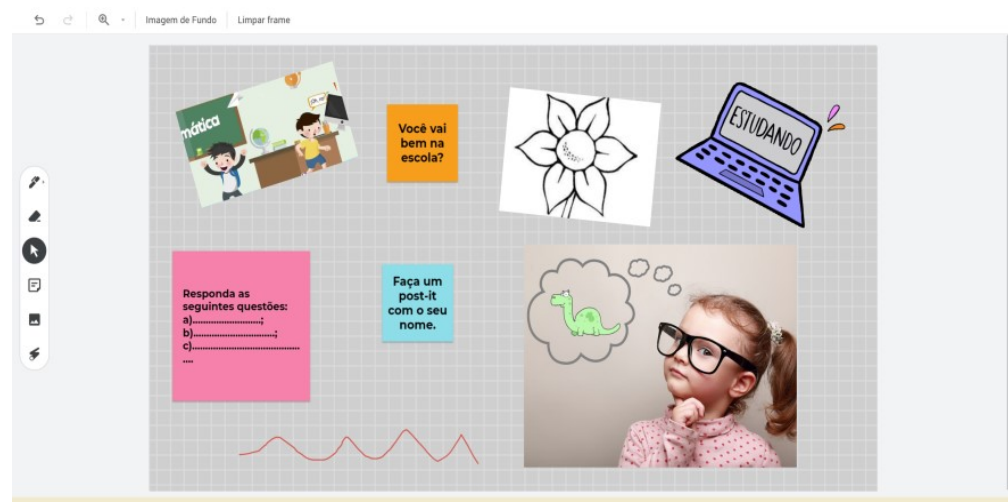

Fonte: Captura de tela da autora, 2020.

O Padlet (Figura 7), um pouco semelhante ao jamboard, tem a tela de fundo decorada e pode ser utilizado para incluir igualmente vídeos, imagens, gifs, textos e conteúdos diversos, também possibilitando interação em tempo real com uma turma de alunos. Na ocasião os inscritos na formação puderam interagir, nessas duas ferramentas, com o professor que ministrava a aula. Enquanto exercitavam ele ia fazendo comentários e solicitando tarefas naquele momento, para realizarem enquanto tivessem a tutoria dele. Por vezes alguém havia perdido o link da tarefa porque estava sem internet ou algo assim, então o professor imediatamente já recolocava o atalho para o participante entrar.

Figura 7 - Tela do Padlet

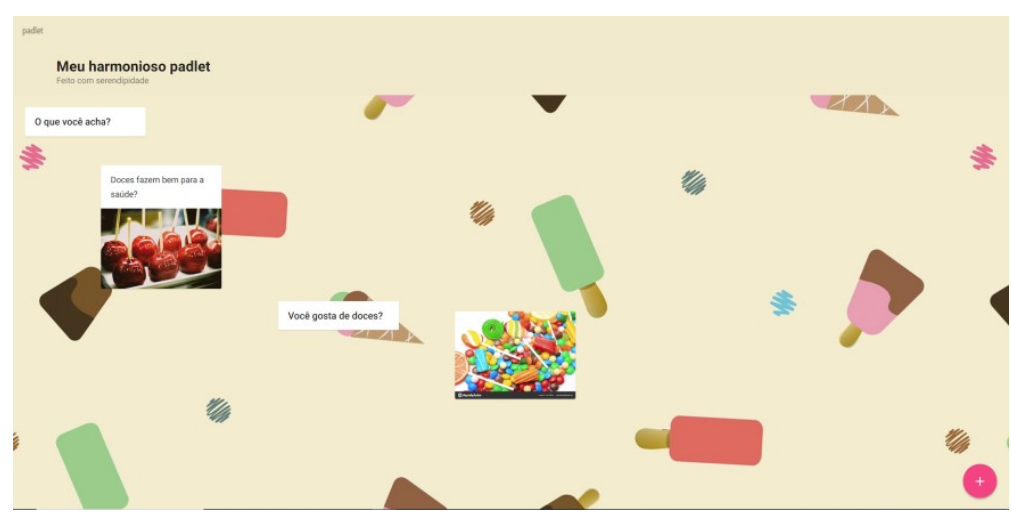

Fonte: Captura de tela da autora, 2020. 
Depois de passar pela experiência de cursos rápidos como este, os inscritos podem ter acesso a outros mais completos e pagos oferecidos pela instituição, através de sua plataforma EAD. Também, durante e após a aula, o professor convida para avaliar a aula e a metodologia utilizada, através de um formulário do google (google forms), do qual ele mesmo passa o link pelo bate-papo.

\section{Possibilidades de formação continuada por e para o Ensino Remoto}

As outras duas experiências das quais trata este trabalho são as dos cursos Expert em Ensino Remoto e Aprender por Projetos, que nesta seção são tratadas relatando-se seu funcionamento e quais ferramentas podem ser trabalhadas pelos professores, mostrando alguns detalhes.

Fazendo uma busca de artigos no scielo ainda não se encontram resultados para a expressão ‘Ensino Remoto'. No entanto, há muitos resultados na internet com os termos, principalmente associados à condição pandêmica a qual vivemos hoje. Diferente do Ensino a Distância (EAD) "uma atividade ou aula remota pode ser considerada uma solução temporária para continuar as atividades pedagógicas e tem como principal ferramenta a internet" (UNICESUMAR.EDU.BR, 2020), o que neste momento de crise é considerado o ideal para minimizar os impactos na aprendizagem de crianças e jovens pela falta da sala de aula presencial, segundo alguns estudiosos. Algumas abordagens inclusive se referem a esta modalidade como Ensino Remoto Emergencial (MOONSHOT EDUCAÇÃO - YOUTUBE, [s.d.], 2020). Também, este formato de ensino não teria uma carga horária composta por diferentes recursos de aprendizado e formatos de atividades e prazos como na modalidade EAD, sendo aplicado apenas durante o período de isolamento social imposto pela pandemia (UNICESUMAR.EDU.BR, 2020).

Durante este período teve-se acesso ao Curso Expert em Ensino Remoto, promovido pela Moonshot Educação, o terceiro exemplo de curso gratuito online destacado neste trabalho. Voltado para escolas, oferece aulas pelo seu canal no youtube, onde apresenta em etapas os assuntos abordados: na semana 
1, aula 1, que foi transmitida ao vivo e disponibilizada em 11 de maio de 2020, abordou $\mathrm{O}$ que é Ensino Remoto Emergencial e por que não é Ensino a Distância. Depois, houve mais duas aulas na mesma semana, sendo uma delas (Figura 8) Por que a comunicação é a chave do sucesso no ensino remoto e como fazer isso da melhor forma possível. Na segunda semana, iniciada em $1^{\mathrm{o}}$ de junho abordaram, também em 3 aulas, temas como Ensino x Aprendizagem, Sala de aula invertida e A gamificação como estratégia ativa de aprendizagem. Na terceira semana, iniciada em 29 de junho, os temas, divididos em 4 aulas, foram Criando um canal com os seus alunos, Jigsaw classroom: a sala de aula quebra-cabeça, Estratégias didáticas assimétricas com google slides e Instrução por pares - metodologia peer instruction. Diferente das duas primeiras propostas relatadas, neste caso não é disponibilizado material para consulta ou tutoriais e instruções. Os professores mostram as ferramentas enquanto explicam como funcionam, ministrando aulas ao vivo.

Figura 8 - Tela de vídeo-aulas do Moonshot Educação no youtube

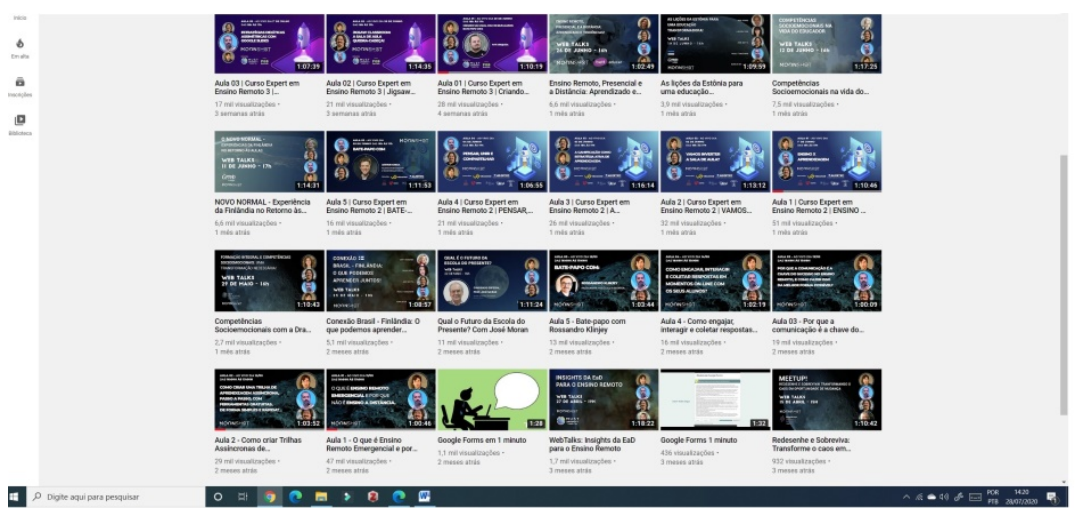

Fonte: Captura de tela da autora, 2020.

Para receber o certificado, que neste caso foi de 12 horas, ao final dos cursos, o inscrito é convidado a fazer algumas atividades de acordo com o tema abordado a cada aula, no google forms disponibilizado junto ao vídeo na plataforma Nutror, onde deve-se apresentar login e senha de acesso. Uma vez inscrito, passa-se a receber notificações pelo youtube, e-mail, telegram e outros canais de comunicação. Nestes cursos há três professores que fazem a mediação com o professor convidado/palestrante, orientam os participantes quanto às inscrições, preenchimento de formulário para certificado, entre outras questões. São também promovidos sorteios de outros cursos e materiais diversos para 
quem preencher determinados formulários. Na aula online ao vivo do youtube entram muitos inscritos, de todo o Brasil, que comentam e interagem com os professores, os quais mostram em tempo real as diferentes ferramentas de aprendizagem propostas nas aulas em funcionamento. A comunicação, que neste caso é síncrona, é bastante descontraída e motivadora, diferente da proposta do curso Extensão em Tecnologias Educacionais, mas semelhante a do Curso de Formação de Professores oferecido pelo UniAraguaia, embora utilize para comunicação o youtube, onde não é possível o inscrito ser visto pelos professores, em vez do zoom, onde professores e alunos veem o professor e podem ser vistos durante todo o tempo de interação. Um inconveniente do modelo de aula ao vivo é que a transmissão pode falhar porque a internet não está funcionando bem ou por outros motivos, então pode-se perder partes das aulas.

A quarta e última experiência escolhida para este relato é a do curso Aprender por Projetos, oferecido pelo Prêmio Respostas para o Amanhã em parceria com o CENPEC Educação, com 20 horas comprovadas em certificado. Semelhante ao curso oferecido pelo SEG, é acessada uma plataforma (Figura 9) com login e senha, mas não AVA, onde se tem acesso a todo o conteúdo do curso, por módulos.

Figura 9 - Tela inicial do curso Aprender por Projetos

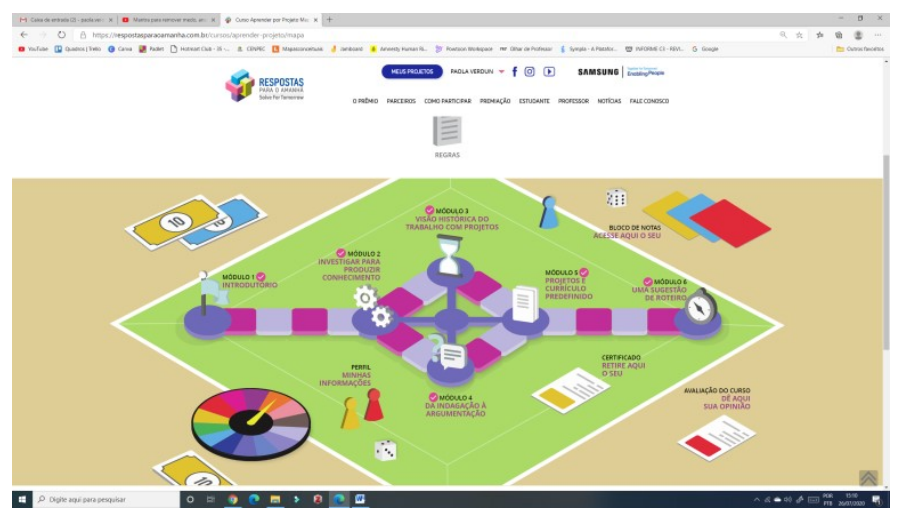

Fonte: Captura de tela da autora, 2020.

Voltado para o ensino médio, é definido um tema e a necessidade dos alunos aprenderem algo. Então, parte-se do pressuposto que aprenderiam mais estudando por projetos onde são os protagonistas de suas pesquisas e 
formalização e publicação dos seus achados, resolvendo problemas reais de sua comunidade. A cada etapa o inscrito tem acesso a textos e imagens e é encaminhado a notícias e casos de projetos reais inscritos no Prêmio Respostas para o Amanhã, mostrando a efetividade da metodologia. $\mathrm{O}$ inscrito deve responder perguntas enquanto avança no conteúdo e algumas de suas respostas devem ser discursivas. Também, o curso disponibiliza todo o conteúdo em pdf para os inscritos, com estratégias para formação de grupos, planejamentos, fichas de acompanhamento, de avaliação, como criar artefatos como jogos, escrita criativa, podcasts, atividade artísticas; entre outras orientações para trabalhar com projetos na escola. Para gerar e receber o certificado é necessário completar todos os módulos, incluindo o último que é a avaliação do curso, mas não é necessário postar conteúdos criados na plataforma, como é o caso do curso do SEG.

\section{Breve análise}

Escolheu-se discorrer sobre formação continuada na experiência de uma mulher, sem filhos, professora, em situação de isolamento social, ou seja, em casa, em suspensão de contrato de trabalho depois de passar por alguns desafios para atender demandas em home office, como a necessidade de adequar equipamentos e condições para gravar vídeos e produzir conteúdos para seus alunos de forma remota. Neste caso, a experiência do isolamento social pode proporcionar uma nova experiência de si, mas, mais do que isso, a oportunidade de produzir a experiência de si, como sugere Larrosa (1994). E isso é possível através de um processo de formação continuada, que, conforme relatado, pode ser realizado online. Como uma experiência que produz efeitos na subjetividade do indivíduo, o estudo das ferramentas online relatadas pode funcionar como um dispositivo pedagógico, ou seja, um "lugar no qual se constitui ou se transforma a experiência de si. [...] lugar no qual se aprendem ou se modificam as relações que o sujeito estabelece consigo mesmo" (LARROSA, 1994, p. 57), dadas as muitas possibilidades de produção de conhecimentos na e para a docência. Assim, proporciona-se um protagonismo da própria formação (CASTRO; AMORIM, 2015, p. 51). 
Por isso a escolha por um relato de experiência com a tecnologia no período de isolamento social, onde outras condições se estabelecem para que uma professora continue em formação e atuando profissionalmente. Condições que também impõem novos olhares e relações sobre si e consigo mesma, onde ocorre uma "ressignificação através das narrativas das histórias vividas. Promovendo uma abertura de espaço às múltiplas possibilidades de ser e de se constituir a partir de si mesma" (REIS; OSTETTO, 2018, p. 4). Não está em foco se houve aprendizagem técnica suficiente para que a professora desempenhe com perfeição e domine absolutamente as ferramentas experimentadas, podendo provar que sabe fazer. Mas sim, como ela se relaciona com o próprio processo de formação e consigo mesma depois de visitar essas novas possibilidades. Trata-se de se dar atenção nas questões ligadas a sua subjetividade, suas emoções, sentimentos, o que tem a ver também com sua autoestima (ANDRÉ, 2013), a partir do momento em que se sente ocupada e progredindo em sua área profissional.

Ainda, em um caso de suspensão de contrato de trabalho onde não se estabelece contato com alunos, nem mesmo pela internet, mas ainda com possiblidades de produzir atividades remotamente, podem surgir questionamentos como "problematização do modelo tradicional de ensino; autoavaliação da prática docente; desenvolvimento de propostas alternativas de ensino, com acompanhamento dos resultados; diálogo entre pares e com os alunos [...]" (HARRES et al., 2018, p. 17). No entanto, ao mesmo tempo em que esse tempo em casa pode ser um tempo para formação continuada e de questionar tudo isso, a exposição às tecnologias digitais é mais intensa. Dentre as propostas alternativas de ensino, foco da EAD ou do Remoto, proliferam alternativas de acesso pela internet, de modo que todo momento, pelo celular, tablet e mesmo pelo computador, chegam notificações pelos apps whatsapp, telegram, instagram, youtube, e-mail, entre outros, o que pode sobrecarregar o profissional de coisas para acompanhar, mesmo em casa. Além disso, também proliferam ofertas para transformar o professor em "“movie maker"; "movie power point"; "webquest", "microsoftvisio" [...]. Além da profundidade de conteúdo, a excelência em recursos audiovisuais e tecnológicos é requerida [...]" (LUZ; BALZAN, 2012, p. 27). Talvez isso se deva ao fato de que, como apontam 
alguns estudiosos, em relação a outros países, o Brasil dá bastante ênfase à formação por EAD com uso das Tecnologias da Informação e Comunicação (KALMUS; SOUZA, 2016), o que faz com que, mesmo com dúvidas, o profissional invista seu tempo de isolamento fazendo os cursos que aparecem na sua área.

Os professores são diferentes, têm histórias diversas, concepções distintas sobre formação contínua, sobre ensino, sobre possibilidades de desenvolvimento próprio e de seus alunos, enfim, apropriam-se à sua maneira da literatura educacional com que entram em contato, assim como das determinações e orientações dos programas educacionais aos quais são submetidos. (SOUZA, 2006, p. 487).

De certo modo, há uma subjetividade docente presa ao princípio contemporâneo de que necessita estar em constante transformação, pois isso é manter-se competente para exercer suas funções. E mesmo pela internet, é possível verificar a necessidade de aprendizagem da pedagogia das competências, onde o professor precisa dominar novas linguagens tecnológicas de ensino (KALMUS; SOUZA, 2016). Por outro lado, a aquisição de novos conhecimentos (CHAMON, 2006) pode proporcionar ao professor ressignificar suas aprendizagens e o que aprende com as novas práticas adquiridas (MAGALHÃES; AZEVEDO, 2015).

\section{Considerações finais}

Este relato de experiência buscou mostrar uma, entre tantas possibilidades, de formação continuada através de cursos online gratuitos durante o período de isolamento social para evitar o contágio pelo covid-19. Além da necessidade de lidar com a situação do enfrentamento da pandemia em segurança, surgiu a necessidade de adaptar recursos para a produção de conteúdo online. Por essa razão é que se escolheu empreender tempo em um treinamento pela internet, na busca por novas ferramentas tecnológicas para ensinar.

Entre os cursos realizados, quatro foram destacados neste trabalho. O primeiro foi o curso Extensão em Tecnologias Educacionais, voltado para professores da $\mathrm{EAD}$, que utiliza um AVA por onde o inscrito navega até completar todas as etapas do curso. O segundo é o curso Formação de Professores: tela inteligente 
online e avaliação online, destinado a professores que atuam na EAD. Todo o curso é ministrado pelo zoom por um professor que interage com os inscritos ao vivo. O terceiro curso é o Expert em Ensino Remoto, voltado para professores de ensino médio com carga horária por Ensino Remoto Emergencial, com aulas também ao vivo, mas pelo youtube. E o quarto e último curso é o Aprender por Projetos, que destina-se também a professores que atuam no ensino médio, utilizando uma plataforma própria para disponibilizar seu conteúdo por módulos, semelhante ao curso Extensão em Tecnologias Educacionais. Os cursos mencionados oferecem certificados, o que oportuniza incluir os dados na plataforma lattes, caso o professor veja importância em manter um currículo acadêmico atualizado.

A experiência de realizar cursos gratuitos online traz diversas reflexões, especialmente no momento que vivemos. Primeiro que, como já foi destacado, a experiência pode constituir-se de uma formação continuada, além de proporcionar a criação da experiência de si de uma professora, mulher que precisa dar conta de si, de seu companheiro, de seu trabalho e da casa durante o período de isolamento. E segundo, que apesar das circunstâncias, adquirir novos conhecimentos e criar novas maneiras de realizar suas práticas pode ser um processo interessante e que inclusive poderá servir de base para outras pesquisas a serem realizadas mais adiante.

\section{Referências}

ANDRÉ, M. Políticas de apoio aos docentes em estados e municípios brasileiros: dilemas na formação de professores. Educar em Revista, n. 50, p. 35-49, dez. 2013 .

CASTRO, M. M. C. E; AMORIM, R. M. DE A. A Formação Inicial e a Continuada: diferenças conceituais que legitimam um espaço de formação permanente de vida. Cadernos CEDES, v. 35, n. 95, p. 37-55, abr. 2015.

CHAMON, E. M. Q. DE O. Um modelo de formação e sua aplicação em educação continuada. Educação em Revista, n. 44, p. 89-109, dez. 2006.

HARRES, J. B. S. et al. CONSTITUIÇÃO E PRÁTICA DE PROFESSORES INOVADORES: UM ESTUDO DE CASO. Ensaio Pesquisa em Educação em Ciências (Belo Horizonte), v. 20, n. o, 16 abr. 2018. 
KALMUS, J.; SOUZA, M. P. R. DE. Trabalho e formação: uma análise comparativa das políticas de formação de professores em serviço no Brasil e no México. Educação e Pesquisa, v. 42, n. 1, p. 53-66, mar. 2016.

LARROSA, Jorge. Tecnologias do Eu e Educação in: SILVA, Tomaz Tadeu da (Org.). O sujeito da educação: estudos Foucaultianos. Petrópolis, RJ: Vozes, 1994 .

LUZ, S. P. DA; BALZAN, N. C. Programa de Formação Continuada para Docentes da Educação Superior: um estudo avaliativo a partir dos resultados de uma tese. Avaliação: Revista da Avaliação da Educação Superior (Campinas), v. 17, n. 1, p. 11-41, mar. 2012.

MAGALHÃES, L. K. C. DE; AZEVEDO, L. C. S. S. Formação Continuada e suas implicações: entre a lei e o trabalho docente. Cadernos CEDES, v. 35, n. 95, p. 15-36, abr. 2015.

MOONSHOT EDUCAÇÃO - YOUTUBE. Disponível em: <https://www.youtube.com/c/MoonshotEduca\%C3\%A7\%C3\%A3o/videos>. Acesso em: 12 jul. 2020.

PRETTO, N. D. L.; RICCIO, N. C. R. A formação continuada de professores universitários e as tecnologias digitais. Educar em Revista, n. 37, p. 153-169, maio 2010.

SANTOS, R. R. M. DOS; MELIM, A. P.; PANIAGO, M. C. L. Formação continuada de professores universitários na rede social facebook: interagir, trocar, dialogar, compartilhar, aprender e conviver. Interações (Campo Grande), v. 18, n. 2, p. 13, 30 maio 2017.

SOUZA, D. T. R. DE. Formação continuada de professores e fracasso escolar: problematizando o argumento da incompetência. Educação e Pesquisa, v. 32, n. 3, p. 477-492, dez. 2006.

Conheça a diferença entre ensino remoto $e$ EAD. Disponível em: $<$ https://www.unicesumar.edu.br/blog/diferenca-entre-ensino-remoto-eead/>. Acesso em: 12 jul. 2020.

Lições do coronavírus: ensino remoto emergencial não é EAD. Desafios da Educação, 2 abr. 2020. Disponível em: <https://desafiosdaeducacao.grupoa.com.br/coronavirus-ensino-remoto/>. Acesso em: 19 jul. 2020.

BRASIL. Diário Oficial da União. Atos do poder executivo. Decreto $n^{\circ}$ 9.057, de 25 de maio de 2017. Regulamenta o art. 80 da Lei $\mathrm{n}^{0}$ 9.394, de 20 de dezembro de 1996, que estabelece as diretrizes e bases da educação nacional. Disponível em: < http://portal.mec.gov.br>. Acesso em: 19 jul. 2020.

o outro. Seus 